\section{Consumer satisfaction}

Consumer satisfaction ratings were strongly supportive of the programme and participants indicated that the sessions fulfilled their needs in terms of education about the various aspects of first-episode psychosis and treatment. Comments made by a number of the participants stated that they wished that this service, and greater support, was available earlier in the admission of their relative (especially those in Group 1) and that there was wider community education about psychosis. A number of participants indicated that if there had been wider community knowledge about psychosis their relative would have been referred to psychiatric services earlier in the course of illness.

\section{Comment}

This programme appears to have value in educating family members about psychosis. Follow-up assessment after a three-month interval will ascertain whether there is a maintenance of gains made from the sessions. It is hoped that future groups will consist of family members earlier in the course of their relative's illness. Future evaluation is aiming to ascertain whether there is reduced family burden as a result of these sessions, in addition to reduced levels of stress in family members.

It must be stressed that this programme is one component of a general treatment strategy to engage families in the management of psychotic illness. Thus, families may require more intensive input in improving skills such as communication, problem-solving, relapse prevention and crisis management.

\section{References}

BarrowClough, C. TARRIER, N.. WATTS, S., et al (1987) Assessing the functional value of relative's knowledge about schizophrenia: a preliminary report. British Journal of Psychiatry. 151, 1-8.

FALLOON, I. R. H., BOYD, J. L., MCGiLl. C. W., et al (1982) Family management in the prevention of exacerbations of schizophrenia. New England Joumal of Medicine. 306, 1437-1440.

JACKSON, C. \& BIRCHWOOD, M. J. (1996) Early intervention in psychosis: opportunities for secondary prevention. British Journal of Clinical Psychology, 35, 487-502.

TARRIER, N. \& BARROWCLOUGH. C. (1986) Providing information to relatives about schizophrenia: some comments. British Journal of Psychiatry. 149, 458-463.

Eric Morris, Clinical Psychologist, Catie Harris, Clinical Liaison Officer; and Lynley Nolan, Clinical Liaison Officer, First Psychosis Liaison Unit, Bentley Health Service, Western Australia

\title{
Children's needs when their mothers are admitted to psychiatric units
}

\author{
Leonor Montoliu Tamarit and A. Yin-Har Lau
}

\begin{abstract}
Aims and methods Due to a concern over the low level of referrals of children to the child and adolescent psychiatry team, an audit was designed to investigate the possible causes. An audit was undertaken in which the case notes of 100 consecutive adult female admissions to acute wards in Goodmayes Hospital were screened. The case notes were screened for mention of children, any actions taken on their behalf. in addition to a number of demographic and social factors.

Results The findings of the audit indicate that children of psychiatrically ill mothers do not receive the
\end{abstract}

attention they need, as indicated by the literature on the topic.

Implications More detailed case history-taking by the parent's psychiatrist and closer cooperation between adult and child psychiatry departments are suggested as two methods of addressing this need.

An audit was undertaken looking at the information obtained in case summaries with regard to children of index adult patients and whether the mental health needs of the children were being met. Data were gathered from the case notes of 
100 consecutive female admissions to acute psychiatric wards at Goodmayes Hospital in Redbridge. Out of these cases, the existence of children was documented in only 24 cases. Fiftythree children aged 0-17 years were identified.

Any mention in the case notes of attempts to identify or cater to the needs of these children was screened. In many cases no inquiries about children were made at all. Often, where children were mentioned, there was insufficient information recorded.

It is recognised in previous reports from professionals working with psychiatrically ill parents, that the children of these parents are not receiving the attention they deserve from mental health services (Goodman \& Isaacs, 1984: further details available from the author upon request). A number of well-designed studies have demonstrated that children of parents with severe psychiatric disorders have a significantly higher risk of developing various kinds of psychopathology than children with parents with no such illness (Rutter \& Quinton 1984: Guinton et al, 1990).

This study was prompted by concerns from the child and adolescent team where we worked, realising that there were very few referrals from the adult psychiatric teams.

\section{The study}

The notes of all female patients admitted to acute psychiatric wards during the six months between July and January 1995 were examined. Data were collected using a proforma including: social demographic data of mothers; type of admission; illness; length of stay in hospital; management. including physical and psychosocial treatments: history of violence; and presence of children. Social demographic data were collected for the children; including the child's involvement in the parent's illness, and exposure to violence. Data were also gathered regarding the existence of partners, relatives or carers and their involvement with or support of the ill parents and their children.

Actions on behalf of the children were also screened. Information was gathered from discharge summaries, all medical entries in the files, follow-up appointments, and correspondence from nursing notes. The results were presented to an audit meeting. It was agreed that there was a need to increase professional awareness of children at risk. A continuation of this study in prospective form was recommended.

\section{Findings}

Out of the 100 case notes of female in-patients studied in the survey, only 24 files indicated the existence of children. Of the 24 female patients, $33 \%$ were between $21-30$ years of age $(n=8), 50 \%$ between $31-40(n=12)$ and $12.5 \%$ between $41-50$ $(n=3)$. One patient had no date of birth on the file. Sixteen per cent of the patients were employed $(n=4)$.

Ten of the 24 women were in the hospital due to informal admissions (41\%). All the remaining patients were admitted under the Mental Health Act. Three patients were admitted under section 5(2), five under Section 2, four under Section 136, one patient under Section 5(4) and one patient under Section 3.

As far as the length of stay in hospital is concerned: eight patients $(33 \%)$ were admitted for less than one month; nine $(37 \%)$ for between one and three months; and one (4\%) patient was admitted for five months. In six of the case files, the patient's length of stay was not documented.

In terms of psychiatric diagnosis, no diagnostic criteria were used (e.g. ICD-10, DSM-IV). Diagnoses were collected from case notes as coded by the psychiatric team and reflected the usual pattern of diagnostic categories found in clinical psychiatric practice. The various diagnoses of

Table 1. Variables screened

\begin{tabular}{lc}
\hline & $n(\%)$ \\
\hline Psychotropic and physical treatments & \\
Treatment & \\
Neuroleptics & $9(37.5)$ \\
Benzodiazepines & $3(12.5)$ \\
Antidepressants & $1(4.2)$ \\
Opiates, methadone & $2(8.3)$ \\
Electroconvulsive therapy & $2(8.3)$ \\
No physical treatment & $7(29.2)$ \\
Psychotherapeutic referral measures & \\
Counselling, community psychiatric nurses & $6(25)$ \\
History of violence & \\
Yes & $8(33.3)$ \\
No & $6(25)$ \\
Toward children & $3(12.5)$ \\
Toward self & $5(28.8)$ \\
Unknown & $10(41.7)$ \\
Children's involvement in parent's illness & \\
Yes & $14(58.3)$ \\
No & $2(8.3)$ \\
Unknown & $8(33.3)$ \\
Children's ages (n=53) & \\
0-7 years & $27(50.9)$ \\
$7-14$ years & $8(15.1)$ \\
14-17 years & $9(17.0)$ \\
17+years & $3(5.7)$ \\
Age not recorded & $6(11.3)$ \\
Number of children per female patient & \\
One child & $8(33.3)$ \\
Two children & $7(29.2)$ \\
More than two children & $9(37.5)$ \\
\hline & \\
\hline & \\
\hline & \\
\hline & \\
\hline &
\end{tabular}


Table 2. Social support to ill parents and children

\begin{tabular}{lc}
\hline & $\begin{array}{l}\text { Number } \\
\text { of cases } \\
(\%)\end{array}$ \\
\hline $\begin{array}{l}\text { Family and social support network } \\
\text { (Relationship to mother) }\end{array}$ & \\
$\begin{array}{l}\text { First-degree relative } \\
\text { Second-degree relative }\end{array}$ & $5(20.8)$ \\
Relatives living abroad & $1(4.2)$ \\
Partner present & $5(20.8)$ \\
Children's carer while mother's admission & $6(25)$ \\
Relatives & $7(29.2)$ \\
Foster Carers & $4(16.7)$ \\
No Information & $13(54.2)$ \\
\hline 1. In only one case was support from relatives clearly \\
documented
\end{tabular}

the 24 patients, and the results from the other screening criteria are contained in Tables 1 and 2 .

\section{Diagnostic criteria}

In reviewing the notes, the mothers evidenced a range of diagnoses: depressive illness, depressive episodes, schizophrenia, psychotic episodes, personality disorders, substance misuse and bipolar affective disorder. There was no correlation between mother's diagnosis and mention of the children in the notes or interventions undertaken on behalf of the children.

\section{Inquiries about children in case notes}

There was inquiry about the children in only seven cases $(29.2 \%)$ but in each case the information was far from being complete. In 17 cases $(70.8 \%)$ no mention was made of the children.

\section{Action taken on behalf of the children}

Three cases (12.5\%) were referred to a mother and baby unit, but only two $(8.33 \%)$ were successful in gaining admission. Social services were contacted in three cases $(12.5 \%)$ but effective action was not taken before the mother's discharge. Two children $(8.33 \%)$ were sent abroad to live with extended families.

\section{Short case vignettes}

\section{Case A}

The mother was admitted under Section 2 of the Mental Health Act suffering from schizoaffective disorder. She reported violence toward her daughter. Professionals involved in the case decided to "refer to child psychiatry in the future". There was no evidence from the case notes that this referral was ever made.

\section{Case B}

A 33-year-old woman, mother of four children, was admitted under Section 3 of the Mental Health Act for two months and treated with electroconvulsive therapy. No inquiries about her children were found in the file.

\section{Case $C$}

A 30-year-old woman, mother of two children was admitted under the Mental Health Act for 78 days with a diagnosis of psychosis. It was mentioned in the case file that the children were "in danger". No actions, however, were taken on behalf of the children.

\section{Comment}

Results of this audit corroborate earlier studies in which a number of instances have been documented of school children in which no inquiry was made concerning the children's psychological health (Vanharen \& La Roche, 1993).

The results of this audit demonstrate that in many cases of admission to Goodmayes Hospital, children of mentally ill parents who are known from the literature to be at high psychosocial risk were neither identified nor assessed. Our study also confirms previous reports that the children of psychiatrically ill parents do not receive the attention they deserve from professionals working with their parents.

In a previous pilot study carried out in Montreal of 100 psychiatric patients, a considerable number had children. In many cases no inquiry had been made concerning the children's psychological health (Vanharen \& La Roche, 1993).

In terms of the physical health of the children, this has not been highlighted in the literature. A. Y.-H. L., however, suggests that physical development and ill-health loading should be included in the child's assessment along with other areas, in particular cognitive, emotional, behaviour at school, mental processes, defences and relationships within family and peer groups.

\section{Recommendations}

To avoid these high-risk children being overlooked, inquiry about their existence and mental health should be part of the psychiatrist's initial evaluation of adult patients. The participation of 
a child psychiatrist in the screening would allow for the detection and follow-up of problems in individual children (Vanharen \& La Roche, 1993). As part of routine history-taking, the presence of children should be recorded in the index patient's case notes.

Basic screening of the needs and welfare of these children should be documented by the adult psychiatric team. Where children are vulnerable, child protection procedures should be initiated via referral to the relevant children and families team in social services.

Closer liaison between adult psychiatric teams and child and adolescent psychiatric teams should be encouraged in order to identify and prevent further damage to children at risk. A prospective research project to detect children of mentally ill parents and to offer an intervention project for their children has been started in Redbridge.

To work in accordance with the spirit of the Children's Act 1989, inter-agency cooperation in providing services for these children in need and their protection should be undertaken. A health professional may be the person to bring a problem to light and express the need for an assessment if there is concern about the child. Court orders under the Act (assessment, protection orders, etc.) can be issued when significant harm is suspected or for a child to be made safe.

Nevertheless, the spirit of the Act is that the best place for the child to be brought up is usually in his/her own home. Therefore, greater collaboration between mental health profes- sionals, parents and their children in meeting their needs would be necessary.

\section{Acknowledgements}

We acknowledge the support of: the Postgraduate Education and Medical Audit Departments, Redbridge Health Care Trust.

\section{References}

Goodman, S. H. \& IsaAcs L. D. (1984) Primary prevention with children of seriously disturbed mothers. Journal of Preventative Psychiatry. 387-402.

GUINTON. D., RUTTER, M. \& GULLIVER. L. (1990) Continuities in psychiatric disorders from childhood to adulthood in the children of psychlatric patients. In Straight and Devious Pathways from Childhood to Adulthood (eds L. Robins \& M. Rutter). Cambridge: Cambridge University Press.

RUTTER, M. \& QUINTON, D. (1984) Parental psychiatric disorder: effects on children. Psychological Medicine. 14. 853-880.

VANHAREN, J. LAROCHE, C. \& HEYMAN, M. (1993) Have the invisible children become visible? Canadian Journal of Psychiatry, 38, 678-680.

*L. Montoliu Tamarit, Registrar in Child and Adolescent Psychiatry. (presently Senior Registrar in Child and Adolescent Psychiatry in UMDS rotational scheme); and A. Yin-Har-Lau, Consultant in Child and Adolescent Psychiatry. Redbridge Health Care Trust, Child and Adolescent Mental Health Directorate, Laxford Hall, Loxford Lane, Iford, Essex IG1 2PL

*Correspondence

\title{
Making sense of child and adolescent mental health services
}

\author{
Paul Stallard and Robert Potter
}

Alms and method A prospective audit of the 425 referrals made to a community child and adolescent mental health service over a three month period was undertaken. Standardised data were collected about the referrer, reason for referral, problem chronicity and complexity, service response and first appointment attendance.

Results The service is currently seeing less than one in five of the children conservatively estimated to require specialist mental health services. The majority of those 